\title{
Die invloed van inligtingstegnologie op werkverskaffing in die Suid-Afrikaanse finansiële sektor
}

\author{
Gideon S. Horn* \\ Departement Ekonomie, Universiteit Vista, Privaatsak X613, Port Elizabeth 6000, Republiek van Suid-Afrika \\ Charles V.R. Wait \\ Depanement Ekonomie, Universiteit van Port Elizabeth, Posbus 1600, Port Elizabeth 6000, Republiek van Suid-Afrika
}

\author{
Ontvang 30 September 1991; aanuaar 23 Januarie 1992
}

\begin{abstract}
The infuence of information technology on the provision of employment in the South African financial sector. The higher levels of productivity in the manufacturing sector, as a result of the automation and other significant changes in production functions, often lead to fears of higher levels of unemployment, as certain types of labour could become redundant. The application of information technology in the form of computers, data banks and telecommunication networks has, to a great extent, contributed to the automation of routine functions, as well as to the integration of various production functions. The danger exists that a great number of workers released from the manufacturing sector are not always trained and suitable for employment in the service sector. In addition, there may not be sufficient employment opportunities to accommodate these workers. The influence of information technology on employment should, however, be considered in terms of the net effect of the three distinguishing effects of information technology on an economy, namely the process, product and organization effects. In South Africa, employment and value added increased in the building society and banking fields during the period 1980-89. Those increases are attributed specifically to the product effect. Since the eighties, banks, building societies and insurance companies have all started to market new and more products that are directly linked to information technology.
\end{abstract}

\begin{abstract}
Hoür vlakke produktiwiteit in die fabriekswese as gevolg van die outomatisering en ander wesenlike veranderings in produksiefunksies, lei dikwels tot vrees vir hot vlakke werkloosheid namate sekere tipes arbeid oorbodig raak. Die aanwending van inligtingstegnologie in die vorm van rekenaars, databanke en telekommunikasienetwerke, het in 'n groot mate bygedra tot die outomatisering van roetinefunksies, sowel as die integrering van verskeie produksiefunksies. Die gevaar bestaan dat die groot aantal werkers wat uit die fabriekswese vrygestel word, nie altyd opgelei of geskik is vir indiensname in die dienstesektor nie, of dat daar nie voldoende werksgeleenthede bestaan ten einde hierdie werkers te akkommodeer nie. Die invloed van inligtingstegnologie op indiensname behoort egter oorweeg te word in terme van die netto effek van die onderskeie gevolge van inligtingstegnologie in 'n ekonomie, naamlik die proses-, produk- en organisasie-effek. In Suid-Afrika het indiensname en toegevoegde waarde in bouverenigings en die bankwese gedurende die periode $1980-89$ toegeneem. Hierdie toenames word spesifiek aan die produkeffek toegeskryf. Sedert die tagtigerjare het banke, bouverenigings en versekeringsmaatskappye begin om al meer en nuwe produkte te bemark wat direk aan inligtingstegnologie gekoppel is.
\end{abstract}

*Aan wie korrespondensie gerig kan word.

\section{Inlelding en doelstelling}

In die ekonomiese literatuur word ekonomiese ontwikkeling en groei gedefinieer as 'n wesenlike en voortdurende toename in die per capita-produk, hoofsaaklik as gevolg van modemer tegnologiese insette (Meier, 1989: 6 \& 8). Kuznets (1966: 1 \& 5) beskou een van die belangrikste eienskappe van modeme ekonomiese groei as hoë koerse van strukturele veranderings in die ekonomie, waartydens ekonomiese aktiwiteite en ekonomiese hulpbronne, hoofsaaklik arbeid, vanuit die landbou na eers die fabriekswese en vervolgens na die dienstesektor verskuif. Die arbeidsmag word tussen die verskillende sektore en beroepe herverdeel, wat gevolglik weer sosiale mobiliteit en die organisasie van werk beïnvloed.

Tydens hierdie strukturele verandering handhaaf die fabriekswese sy režle posisie ten opsigte van sy absolute bydrae tot die BBP en brei dit selfs uih maar vermag dit wel met 'n kleiner arbeidsmag. Dit dui op hoer produktiwiteit in die fabriekswese, hoofsaaklik as gevolg van wesenlike veranderings in produksiefunksies (Nicolaides, 1989: 22). Die fabriekswese is voortdurend onderworpe aan veranderings in produksiefunksies, veral as gevolg van doeltreffender en modemer insette wat op volgehoue uitvindsels en tegnologiese vooruitgang in hoofsaaklik die dienstesektor gebaseer is. Hierdie dienste-insette bestaan veral uit besigheids- en infrastrukturele dienste en sluit navorsings-, ontwerp-, ingenieurs-, verspreidings-, dataverwerkings- en finansiële dienste in. Die rol van dienste-insette word verder verhoog as gevolg van grootskaalse veranderings in inligtings- en kommunikasietegnologie, wat tot verdere verhogings in die fabriekswese se produktiwiteit aanleiding gee.

Meer gemeganiseerde produksietegnieke wat produktiwiteit in die fabriekswese verhoog, maak sekere tipes arbeid in die fabriekswese oorbodig. Die oorbodige arbeid in die fabriekswese as gevolg van hour produktiwiteit, raak oorwegend vir die dienstesektor beskikbaar en namate dié arbeid in dié sektor in diens geneem word, word die relatiewe groeikoers van sektore gehandhaaf. Die gevaar bestaan egter dat 'n groot aantal werkers wat op hierdie wyse uit die fabriekswese ontslaan word, nie altyd geskik en opgelei is vir betrekkings in die dienstesektor nie, of dat daar nie voldoende werksgeleenthede in die dienstesektor sal bestaan ten einde hierdie werkers te akkommodeer nie. So 'n situasie kan dus tot werkloosheid in die formele arbeidsmark aanleiding gee.

Die beweging van arbeid uit die fabriekswese na die dienstesektor, is soortgelyk aan dié van arbeid vroeer vanuit die landbousektor na die fabriekswese as gevolg van hoér 
produktiwiteit in die landbousektor (Houghton, 1973: 67). Die hoèr vlakke van produktiwiteit in hierdie geval is veral deur die gebruik van doeltreffender inseue, vanaf hoofsaaklik die fabriekswese, teweeg gebring. Voorbeelde hiervan sluit in: beter plaasgereedskap, meganiese toerusting en chemiese kunsmis.

Die doel van hierdie artikel is om te let op die invloed wat inligtingstegnologie en gevorderde dienste-insette op werkverskaffing in die algemeen, maar veral in die finansie̋le sektor in Suid-Afrika, uitoefen. Die werkverskaffingsproses is tot redelik onlangs in beginsel as 'n stabiele en eenvoudige inset-uitsetverhouding bestempel. Hiervolgens vereis die produksie van enige produk ' $n$ vasgestelde kombinasie insette van kapitaal, arbeid en grondstowwe ten einde ' $n$ verlangde eenheid uitset voort te bring (Rajan, 1987: 13). Die aanwending van nuwe inligtingstegnologie, tegnologiese voonitgang en moderne ontwikkelings wat voortdurend in die fabriekswese geïnkorporeer word en daanoe bydra dat produksiefunksies verander, het egter tot gevolg dat indiensname en werkverskaffing nie meer net met 'n konstante inset-uitsetberekening beoordeel kan word nie.

\section{Rol van Inligtingstegnologle in die hedendaagse produksleproses}

Hoofsaaklik as gevolg van hul hoæ graad van betroubaarheid, dalende eenheidskoste en verbruikersvriendelikheid, is inligtingskomponente soos rekenaars, databanke en telekommunikasienetwerke deesdae baie toegankliker vir veral ontwikkelende ekonomieè as wat die geval was met die hoofraam-rekenaartegnologie van vroeer. Inligting vorm tans inderdaad die gemeenskaplike basis van die dienstesektor (Lanvin, in Bressand \& Nicolaïdis, 1989: 106).

Dit dien as belangrike intermediêre inset in feitlik alle modeme produksie-aktiwiteite en bedien as't ware ander dienste- en vervaardigingsbedrywe. Die aanwending van die mees gevorderde en moderne inligtingstegnologie, hoofsaaklik weens hodr produktiwiteit, asook groter stoor-, vervoer- en verhandelbaarheid, maak die dienstesektor toenemend tegnologie-georiënteerd, sodat werkmetodes, produkmengsels en organisasiestrukture voortdurend verander.

Die toenemende hoeveelheid inligting wat benodig word om goedere en dienste te produseer, tesame met die ontwikkeling van suiwer inligtingsprodukte, word deur Rada (in Giarini, 1987: 132) na verwys as die 'informatization of society' en impliseer 'n hoer tegnologiese inhoud in landbou-, fabrieks- en diensteproduksie. Dit het vinniger, goedkoper en doeltreffender geword om inligting elektronies te versend en te stoor, met die landbou-, die sekondêre en die dienstesektor wat voordeel trek uit skaalvoordele wat moontlik gemaak word deur gesentraliseerde produksie en die elektroniese verspreiding van dienste. As gevolg van die toenemend belangrike rol wat inligting in veral besigheidsdienste soos finansiële dienste, ingenieurswese, asook marknavorsing en ontwikkeling betrokke by industrialisasie speel, is inligtingstegnologie tot feitlik 'n produksiefaktor in eie reg verhef (Lanvin, in Bressand \& Nicolaïdis, 1989: 105).

Die aanwending van inligtingstegnologie dra grooliks by tot die outomatisering van roetinef unksies, die verbetering van die produktiwiteit van landbou-, fabrieks- en diensteaktiwiteite, asook die integrering van verskeie produksiefunksies. Inligtingstegnologie se vermos het ook daanoe bygedra dat die vier bekende en tradisionele kantoorpligte, naamlik die versameling, verwerking, berging en herwinning van inligting, geoutomatiseer is. Dit is as gevolg van die aard van hul roetinetake, dat veral klerklike funksies en dag-tot-dag administratiewe funksies gestandardiseer en geoutomatiseer word. Selfs strategiese funksies soos dié van beplanning en bemarking steun toenemend op inligtingstegnologie vir groter doeltreffendheid.

Inligtingstegnologie het veral 'n groot invloed op die gebiede van die bankwese, versekering, konsultasie en die ingenieurswese (Roach, 1985: 20). Hierdie dienstenywerhede is, hoofsaaklik as gevolg van die beskikbaarheid van rekenaars en verbeterde kommunikasienetwerke, in staat om 'n veel wyer reeks dienste teen 'n hoerr spoed en laer koste aan verbruikers te verskaf. Daar word vanuit 'n werkskeppingsoogpunt soms met kommer gelet op die toename in alledaagse dienste-aktiwiteite soos die gebruik van outomatiese tellermasjiene by banke, selfbediening deur middel van telebank- en telekoopfasiliteite, die koop van 'n bus- of treinkaartjie by ' $n$ outomatiese masjien, asook selfbediening in afdelingswinkels en hipermarkte. Dit skyn asof selfs bestuurders en administrateurs die risiko loop om hul werk te verloor deurdat minder toesig benodig mag word.

\section{Invloed van Inligtingstegnologle op werkverskaf- fing in finanslêle instellings}

Gegewe die bogenoemde impak van inligtingstegnologie, tesame met die feit dat die fabriekswese as gevolg van houtr produktiwiteit potensieel al hoe minder werksgeleenthede skep, kom die dienstesektor as altematiewe bron van werkskepping naas die primêre en sekondêre sektore, loenemend onder die soeklig. Kommer bestaan in verskeie oorde dat die vermos van inligtingstegnologie om tradisionele take baie vinniger as fisiese arbeid te vollooi, die gebruik van kapitaalloenusting ten koste van arbeid verder sal bevorder.

Die vervanging van arbeid deur kapitaal hou uiteraard negatiewe implikasies vir werkskepping in (Barras, 1986: 763). Produksiewerkers se vermoěns, gebaseer op jare se ondervinding en opleiding, word byvoorbeeld ondermyn deur 'n onpersoonlike stelsel van onder meer rekenaars wat hoerr vlakke van werkverrigting bied. Hierdie tendens het verder die potensiaal om die persoonlike verhouding wat tussen diensteverbruikers en dienstevoorsieners bestaan, soos in die geval van dokter en pasiènt, onderwyser en leerling, prokureur en kliënt, in te krimp of heeltemal te vernietig. Hartwell (1978: 384) sluit hierby aan en verklaar dat modeme industrialisasie die verhouding tussen bestuurder en werknemer in die arbeidsmark verander het, terwyl die samevoeging van 'n groot aantal werkers in dieselfde werkplek, ook nuwe sosiale probleme vir die werkersklas geskep het.

Rajan (1987: 21) het in 'n studie bevind dat inligtingstegnologie die volgende drie onderskeibare invloede op 'n ekonomie en in besonder indiensname het, naamlik 'n proses-, produk- en organisatoriese effek. 


\section{Proseseffek van inligtingstegnologie}

Die proseseffek verwys na verlore indiensname as direke gevolg van die outomatisering van produksie-, oordrag- en behoerprosesse (Rajan, 1987: 21). Dit berus op die veronderstelling dat inligtingstegnologie die inhoud en vorm van die inset-uitsetverhouding beïnvloed deundat werknemens deur kapitaaltoerusting vervang word.

Dit is veral op die gebied van finansiele dienste, asook verspreidings-, kommunikasie- en persoonlike dienste, waar inligtingsdienste die belangrikste rol in die rasionalisering van roetinefunksies speel en fisiese arbeid bespaar. Hotelle maak byvoorbeeld toenemend van rekenaars gebruik om roetinefunksies soos besprekings, verrekenings en voorradbeheer te outomatiseer. In die bankwese en versekering is dit outomatiese tellermasjiene (OTM's) en kragtige rekenaars, wat funksies soos die direkte inbetaling van salarisse in persoonlike rekenings, saldo-navrae, verrekenings en onmiddellike premiekwotasies vir verskillende versekeringsdienste outomaties en teen lae eenheidskoste, verrig.

Klerklike personeel word in 'n groot mate deur hierdie proseseffek vervang, terwyl selfbediening deur die verbruiker toeneem. In die algemeen wil dit dus voorkom asof die proseseffek as sodanig 'n negatiewe uitwerking op werkverskaffing kan hê. Dit kan egter ook positief wees in gevalle waar nuwe stelsels tot die ontwikkeling van spesialis- en nuwe vaardighede lei en nie bestaande vaardighede direk vervang nie.

\section{Produkeffek van inligtingstegnologie}

Die produkeffek hou verband met ' $n$ ' toename in werksgeleenthede wat hul oorsprong het in die ontwikkeling van nuwe goedere en dienste as gevolg van die gebruik van inligtingstegnologie (Rajan, 1987: 22). Tegniese vooruitgang het nie slegs nuwe en meer produktiewe metodes ontwikkel ten einde bestaande produkte te verbeter en behoeftes te bevredig nie, maar ook nuwe produkte en nuwe behoeftes geskep (Thirlwall, 1982: 31). So byvoorbeeld het die wasmasjien, stofsuier, video-opnemer, sakrekenaar en persoonlike rekenaar veel meer nuwe behoeftes en nuwe werksgeleenthede geskep as wat vernietig is.

Die gebruik van inligtingstegnologie in finansielle dienste het tot kwantitatiewe toenames in arbeidsproduktiwiteit, produkverskeidenheid, kostebesparings en verbeterings in die kwaliteit van dienste gelei (Howells, 1988: 88). 'n Sprekende voorbeeld hiervan is die moderne kredietkaar wat vir banksake en vir aankope gebruik kan word. Die groter verskeidenheid van funksies wat as gevolg van verbeterde tegnologie teen 'n hở spoed met behulp van 'n kredietkaan gedoen kan word, spreek die modeme verbruiker aan en dien terselfdertyd as uitstekende bemarkingsinstrument.

Op die gebied van versekering het die vermož van groot rekenaarstelsels die ontwikkeling van massa gestandaardiseerde, verbruikergerigte dienste bevorder. By bouverenigings lei die nuwe beskikbare dienste tot onder meer toenemende spaar- en huiseienaarskapstransaksies, wat op hul beurt weer tot groter besigheidsvolume en taknetwerke lei.

Die aantal en verskcidenheid finansiěle produkte wat aan klante gebied word, het gedurende die afgelope jare dan ook skerp toegeneem en die toename is as't ware groter as die coename in klièntegetalle (Rajan, 1987: 23; Thirlwall, 1982: 31). Koste-effektiewe werkmelodes en deregulering as gevolg van die gebruik van modeme inligtingstegnologie het finansiexle instellings gevolglik in staat gestel om hul dienste-aktiwiteite te vermeerder, hul geografiese markte te vergroot, nuwe produkte te ontwikkel en werkverskaffing te bevorder.

In al die bogenoemde gevalle het die groter sakevolume ook groter persoonlike skakeling tussen personeel en kliènte insake navrae, eisehantering, die verwerking van nuwe aansoeke, asook skakelwerk met makelaars tot gevolg. Dit lei op sigself nie net tot 'n groter mate van werkverskaffing nie, maar kan ook tot 'n groter mate van werksverryking en werkstevredenheid aanleiding gee.

\section{Organisatoriese effek van inligtingstegnologie}

Hierdie derde effek het veral 'n invloed op die beheerfunksie van firmas. Die organisatoriese effek laat nie slegs die outomatisering van beheerfunksies we deur die vermindering van toesighouers nie, maar akkommodeer oak organisatoriese ontwerp wat tot skaalvoordele en groter doeltreffendheld bydra (Rajan, 1987: 21). Die modeme supermark en hipermark is goeie voorbeelde van organisatoriese innovasie wat sterk op rekenaartegnologie steun.

Die gebruik van aftasters by betaalpunte hou byvoorbeeld rekord van verkope en voorrade en verhoog daardeur die produktiwiteit van arbeid. Die organisatoriese effek impliseer dat die rol van die bestuurder al sterker op die voorgrond tree, en inligtingstegnologie vereis in der waarheid 'n nuwe tipe bestuur.

Spoed en betroubaameid van inligting is tans baie belangrik en word deur rekenaartegnologie gesteun. Veral wat finansiěle dienste betref, is markte lewendiger, wisselkoesse en rentekoerse fluktweer meer, die omvang van finansielle instrumente soos verbande en aandele neem toe en dit word komplekser van aard. Bestuurders maak gevolglik wenemend van rekenaars vir konferensiedoeleindes, onderstevning- en inligtingstelsels, databanke, en dies meer, gebruik.

Volgens Drucker (1988: 2) sal die organisasie van die moderne onderneming in die toekoms al meer op inliging gebaseer wees en sal die werkerskorps grootliks uit spesialiste bestaan. Bestuur sal min ooreenstemming met die huidige en tradisionele opdrag- en beheerfunksie toon, wat steads as die norm in die meeste handboeke voorgehow word. Deurdat daar toenemend van inligtingstegnologie gebruik gemaak word, sal die besluitnemingsproses, bestuurstruktuur en die wyse waarop werk verrig word, verander.

Die belangrikste uitvloeisel hiervan is dat die aantal bestuurders en die vlakke van bestuur sal krimp, met veral middelpersone in bestuur wat sal verminder en heelwat bestaande bestuurders oorbodig sal maak. Die teenwoordigheid van meer spesialiste in die werksituasie kan tot gevolg hê dat werknemers hul eie prestasies bestuur en dissiplineer deur middel van die georganiseerde terugvoering van kollegas, kliènte en hoofkantoor. Dit bevestig weer cens die gespesialiseerde kennis en opleiding wat van die modeme bestuurder verlang word.

Dit is duidelik dat, ten einde die invloed van inligtingstegnologie op werkskepping te bepaal, die netto effek van die drie genoemde en interafhanklike effekte in sy geheel 
bestudeer moet word. Inligtingstegnologie lei op die oog af tot die totstandkoming van 'n groot verskeidenheid nuwe produkte en veranderings in produksie wat aan die een kant kapitaal, arbeid, materiaal en energie bespaar, maar aan die ander kant tot 'n selfs groter verbruik van hierdie produksiefaktore kan lei. As gevolg van die feit dat die drie nie individueel gekwantifiseer kan word nie, moet die netto effek van inligtingstegnologie eerder in kwalitatiewe terme uitgedruk word.

Navrae by vaste eiendoms-, versekerings- en finansiële dienste-instellings in Suid-Afrika, dui daarop dat die proses-, produk- en organisatoriese effekte soos hierbo verduidelik is, wel in Suid-Afrika posgevat het, alhoewel die presiese omvang daarvan om etiese redes nie in absolute terme gekwantifiseer kan word nie.

In Tabel 1 word die werkverskaffingsyfer en die ooreenstemmende reěle jaarlikse syfer van die toegevoegde waarde, uitgedruk in konstante 1985-pryse, in die Suid-Afrikaanse bankwese, versekeringswese en bouverenigings vir die periode 1980-89, aangetoon. Die twee reekse syfers, naamlik indiensname en toegevoegde waarde, is vir elke subsektor met behulp van die TSP-rekenaarprogram gekorreleer. Die korrelasie-koëffisiènte $(r)$ verskyn onder aan die tabel en is vir die bankwese, versekeringswese en bouverenigings op onderskeidelik $0.992,-0.347$ en 0.949 bereken.

Tabel 1 se gegewens dui eerstens dasrop dat gesamentlike indiensname in die bankwese, versekering en bouverenigings vir die genoemde tydperk in Suid-Afrika in totaal met gemiddeld $46.7 \%$ of gemiddeld $4.67 \%$ per jaar toegeneem het. Die individuele toename in werkverskaffing van die drie subgroepe vir die tydperk $1980-89$ is soos volg bereken: bankwese (37.1\%), versekering $(70.1 \%)$ en bouverenigings (32.8\%).

Tabel 1 Jaarlikse werkverskaffing en toegevoegde waarde in die bankwese, versekering en bouverenigings in Suid-Afrika 1980-89

(Getalle)

\begin{tabular}{ccccccc}
\hline Jaar & \multicolumn{2}{c}{ Bankwese } & \multicolumn{2}{c}{ Versekering } & \multicolumn{2}{c}{ Bouverenigings } \\
\hline & $\begin{array}{c}\text { Indiens- } \\
\text { name } \\
(\text { Getal })\end{array}$ & $\begin{array}{c}\text { Bydrae } \\
\text { to BBP } \\
(\mathrm{Rm})\end{array}$ & $\begin{array}{c}\text { Indiens- } \\
\text { name } \\
(\text { Getal })\end{array}$ & $\begin{array}{c}\text { Bydrae } \\
\text { to BBP } \\
(\mathrm{Rm})\end{array}$ & $\begin{array}{c}\text { Indiens- } \\
\text { name } \\
(\text { Getal })\end{array}$ & $\begin{array}{c}\text { Bydrae } \\
\text { to BBP } \\
(\mathrm{Rm})\end{array}$ \\
\hline 1980 & 69178 & 2075 & 36973 & 869 & 16635 & 1489 \\
1981 & 75253 & 2349 & 39594 & 914 & 18132 & 1561 \\
1982 & 79931 & 2466 & 42684 & 863 & 19066 & 1703 \\
1983 & 83535 & 2549 & 46121 & 883 & 19949 & 1784 \\
1984 & 88584 & 2731 & 48255 & 900 & 20588 & 1982 \\
1985 & 88734 & 2794 & 50967 & 865 & 20871 & 2032 \\
1986 & 87928 & 2758 & 50794 & 867 & 21021 & 2111 \\
1987 & 88059 & 2739 & 53169 & 900 & 20966 & 2223 \\
1988 & 92614 & 2925 & 58478 & 867 & 21391 & 2294 \\
1989 & 94870 & 3073 & 62877 & 859 & 22089 & 2360 \\
\hline
\end{tabular}

$r=0.992 \quad r=-0.347 \quad r=0.949$

Bron: Suid-Afrikaanse Reserwebank: Ongepubliseerd.
Die korrelasie-koëffisiěnte (r) van 0.992 en 0.949 in die geval van onderskeidelik die bankwese en bouverenigings toon 'n sterk positiewe korrelasie tussen die tydreekse aan. Dit dui op 'n sterk moontlikheid dat, ceteris paribus, stygende indiensname in albei hierdie sektore met 'n feitlik ooreenkomstige persentuele toename in toegevoegde waande gepaardgaan. Die korrelasie-koëffisiěnt wat in die geval van versekering bereken is, naamlik -0.347 , toon dat geen afleiding in terme van ' $n$ moontlike verband tussen indiensname en toegevoegde waarde vir hierdie sektor gemaak kan word nie.

Die feit dat indiensname by bankwese, versekering sowel as bouverenigings gedurende die tydperk 1980-89 toegeneem het, laat die vermoede ontstaan dat die groter mate van werkverskaffing wel aan die proses-, produk- en organisatoriese effekte toegeskryf kan word. Daar is reeds vroeerr aangedui dat die bydrae van elk van die effekte nie in absolute terme gekwantifiseer kan word nie. Die ontstaan van nuwe produkte en dienste as gevolg van inligtingstegnologie - die sogenaamde produkeffek - het werkverskaffing in Suid-Afrika dus gestimuleer. Gedurende die tagtigerjare het banke byvoorbeeld verskeie nuwe produkte begin bemark wat direk aan inligtingstegnologie gekoppel kan word. Bo en behalwe die bekende krediekkarn, sluit ander nuwe produkte die volgende in: garagekaarte, sleutelkaarte, bankteldienste, 'n verskeidenheid beleggingsprodukte, asook 'n groter verskeidenheid dienstefunksies wat deur outomatiese tellermasjiene gelewer kan word.

Die omskakeling van bouverenigings in banke het ook tot groter werkverskaffing in eersgenoemde gelei. Bouverenigings ding tans toenemend met banke mee in die lewering van dienste soos persoonlike lenings, tjekfasiliteite en kredieckaane. 'n Groter werkerskorps word benodig om die groter volume nuwe produkte en kliënte te hanteer. Meer makelaars word ook in diens geneem deurdat bouverenigings tans toenemend hul kliënte se eie versekering behartig en hulle ook aangaande beleggingsmoontlikhede adviseer. Spesialiste wat voorheen in banke gewerk het, is veral na die topbestuur van bouverenigings gelok ten einde dié bedryf in staat te stel om by veranderende finansièle omstandighede aan te pas. Die ornvang van 'n moontlike netto toename in topbestuurindiensname, as gevolg van hoof saaklik die produkeffek, word in 'n sekere mate deur die publikasie van syfers deur dic Sentrale Statistiekdiens in verband met vakatures wat vir besturende, uitvoerende en administratiewe werkers bestaan, geillustreer (RSA, 1989: 207). Die aantal vakatures het vanaf 1508 in 1977 tot 7247 in 1987 toegeneem, dus ' $n$ toename van $380.6 \%$.

Die beskikbaarheid van meer produkte het ook op versekeringsgebied meer werksgeleenthede vir bemarkers en adviseurs geskep. As gevolg van inflasie het die publiek meer bewus geword van versekering ten einde voorsiening te maak vir gebeure soos dood, ongeskiktheid en aftrede. Nuwe produkte wat veral gedurende die tagtigerjare bemark is, sluit onder meer die volgende in: trauma-versekering teen hartaanvalle en kanker, tienjaar-beleggingsplanne wat belastingvoordcle inhou, asook beleggings wat voorsiening maak vir studiegeld. Die Suid-Afrikaanse publiek spaar tans eerder by wyse van versekering in die vorm van annuïteite en effektetrusts as by wyse van die konvensionele bank- en poskantoorrekeninge. 


\section{Samevatting}

Uit die bogenoemde bespreking wil dit voorkom asof die groter gebruikmaking van die rekenaar in Suid-Afrika se finansiele sektore, indiensname nie so nadelig beïnvloed soos wat aanvanklik verwag of selfs gevrees is nie. Die beskikbaarheid van 'n groter verskeidenheid produkte en dienste in die vaste eiendoms-, versekerings- en finansiêle dienste-instellings, het tot gevolg dat die omvang van rekenaartoevoer en -afvoer steeds weneem en meer werknemers verg om inligting na te gaan en te verwerk. 'n Groter aantal rekenaargeletterde persone word ook in diens geneem ten einde die nodige rekenaarprodukte en -stelsels daar te stel, verder te ontwikkel en in stand te hou.

\section{Summary}

Information services in the form of computers, data banks and telecommunication networks, have become the common and most important intermediate input in almost all modem production activities and serve other service and manufacturing enterprises. The application of information technology has to a great extent contributed to the automation of routine functions, as well as the integration of various production functions.

Information technology has great influence on specifically the fields of financial and distribution services, distribution, consultation and engineering. Fear exists in various circles that the capacity of information technology to complete traditional tasks much faster than physical labour, will benefit the use of capital equipment at the expense of labour.

The influence of information technology on employment should, however, be considered in terms of the three distinguishing effects of information on an economy, namely the process, product and organization effects. The process effect refers to lost employment due to the automation of production, transfer and control processes. The product effect concerns the increase in job opportunities which originate from the development of new goods and services as a result of the use of information technology. The organization effect influences the control functions of firms. It implies that the role of the manager is brought stronger to the fore, with information technology in effect requiring a new type of management.

In South Africa, employment and value added have increased in the building society and banking fields during the period 1980-89. These increases are attributed to the product effect specifically. The origin of new products and services as a result of information technology - the socalled product effect - has stimulated employment in South African banks and building societies. During the eighties banks have started to market new products that are directly linked to information technology. These products include the well-known credit card as well as garage cards, key cards, banktel services, various investment products and different autobank services. The change over of building societies into banks has led to higher employment in the former.

The availability of more products has also created more job opportunities in the field of insurance. New products which have been marketed since the eighties, include ten year investment plans with tax advantages, investments that make provision for study, as well as trauma insurance against heart attacks and cancer.

In order to determine the influence of information technology on employment, it is therefore necessary to study the net effect of the three above-mentioned and interlinked effects. It appears as if the use of the computer in the South African financial sectors, has not influenced employment as negatively as was initially feared.

\section{Erkenning}

Geldelike bystand, gelewer deur die Sentrum vir Wetenskapontwikkeling (voorheen RGN: INO) vir hierdie navorsing, word hiermee erken. Menings wat in hierdie publikasie uitgespreek is en gevolgtrekkings waartoe gekom is, is dié van die outeurs en nie noodwendig dié van die Sentrum vir Wetenskapontwikkeling nie.

\section{Verwysings}

Barras, R. 1986. New technology and the new services. Fulures, December: 748-772.

Drucker, P.F. 1988. The coming of the new organisation. Dialogue, No. 82: 2-7.

Hartwell, R.M. 1978. The service revolution: the growth of services in modem economy. In The Fonsana economic history of Europe, Capella, C.M. (ed.). Glasglow: William Collins.

Houghton, D.H. 1973. The Soush African economy. 3rd ed. Cape Town: Oxford University Press.

Howells, J. 1988. Economic, technological and locational trends in European services. Gower: Brookfield.

Kuznets, S. 1966. Modern economic growth: rate, structure and spread. Connecticut: Yale University Press.

Lanvin, B. 1989. Information, services and development. In Strategic trends in services, Bressand, A. \& Nicolädis, K, (eds.). New York: Harper \& Row Publishers.

Meier, G.M, 1989. Leading issues in economic development. 5th ed. New York: Oxford University Press.

Nicolaides, P. 1989. Liberalizing service trade. London: The Royal Institute of International Affairs.

Rada, J.F. 1987. Information technology and services. In The emerging service economy, Giarini, O. (Ed.). Oxford: Pergamon Press.

Rajan, A. 1987. Services - the second industrial revolusion? London: Butterworths.

Republiek van Suid-Afrika. Sentrale Statistiekdiens. 1989. SuidAfrikaanse Arbeidstatistieke. Pretoria: Staatsdrukker.

Roach, S.S. 1985. The information economy comes of age. Information Management Review, Vol. 1, No. 1: 9-18.

Suid-Afrikaanse Reserwebank. Ongepubliseet de data.

Thirlwall, A.P. 1982. Deindustrialisation in the United Kingdom. Loyds Bank Review, No. 144: 22-37. 